\title{
The Game Theory in Development of Internet of Things
}

\author{
Kai MA \\ School of Marxism, Henan Agricultural University \\ Henan Agricultural University Zhengzhou, P.R. China \\ e-mail: makai1230@126.com
}

Keywords: the Internet of Things; Game Theory; development

\begin{abstract}
The Internet of Things (IOT), "The Third Wave of information industry", has brought more and more people to pay attention to. Within the framework of game theory, this paper analyzes the relationship between consumers and the Internet of Things. The results indicate that the active consumption in the some extent could promote the development of IOT, but is limited. Only the dynamic balance between consumers and IOT be held and kept steadily, can the development of IOT have a bright future.
\end{abstract}

\section{Introduction}

In the year 2009, "the Internet of Things" swept the whole of China, and drew wide attention on a great number of people. In the same year, the premier Wen visited WSN and pointed out that it is necessary to make every efforts to develop IOT(short for "the Internet of Things") [1].

There is no doubt that the development of IOT is inseparable from a mutual and perfect market, which has the ability to put consumers and IOT be connected and then further promote the development of IOT.

Though plenteous achievements has been obtained in the previous studies of IOT, there is little discussion on the relationship between consumers and IOT. Within the game theory framework, this paper takes an attempt to analyses the latent interaction between consumers and IOT, in order to push the development of IOT greatly.

\section{The Definition of "the Internet of Things"}

Connections will increase and create an entirely new mazy network of networks-an Internet of Things [2] (see the following figure). IOT is neither science fiction nor industry hype, but is based on solid technological advances and visions of network ubiquity that are energetically being realized. IOT is the seventh in the series of "ITU Internet Reports", originally launched in 1997 under the title "Challenges to the Network". Due to the lack of internationally criterion, the definition of "Internet of Things" has still some fuzziness, and can have many different views depending on the scholars. 


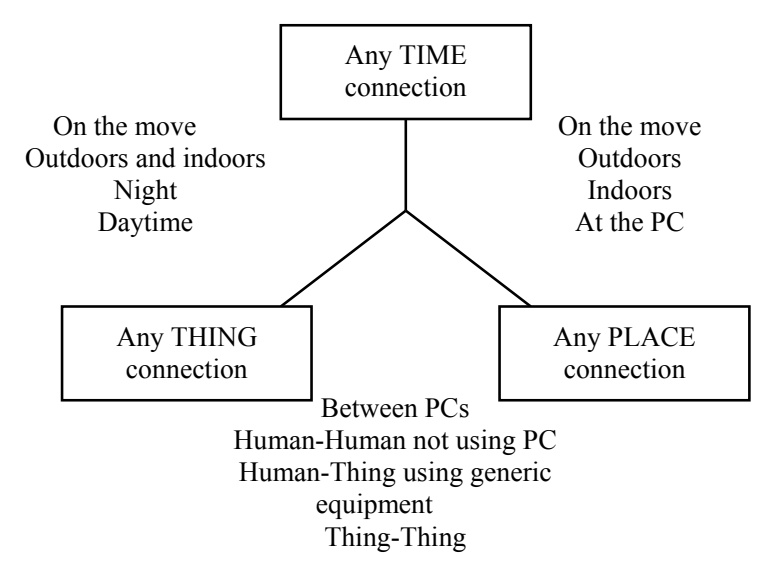

Figure 1. The Definition of the Internet of Things

The first view: Considering the functionality and identity as core it is reasonable to define the IOT as "things having identities and virtual personalities operating in smart spaces using intelligent interfaces to connect and communicate within social, environmental, and user contexts [3]."

The second view: some scholars argue that "the Internet of Things" is a new kind of technology. This view puts the focus on the seamless integration, which could be formulated as "Interconnected objects having an active role in what might be called the Future Internet".

The third view: "the Internet of Things" is a global network infrastructure, linking physical and virtual objects through the exploitation of data capture and communication capabilities. This infrastructure includes existing and evolving Internet and network developments [4]. It will offer specific objectidentification, sensor and connection capability as the basis for the development of independent federated services and applications. These will be characterized by a high degree of autonomous data capture, event transfer, network connectivity and interoperability.

Base on the above analysis, "the Internet of Things" is a kind of modern technology, implicating machine to machine communications and person to computer communications will be extended to everything, from everyday household objects to sensors monitoring the movement.

\section{The Status Quo and Prospects of IOT's Industry in Foreign Countries and China}

The development of Internet of Things have been for nearly fifteen years, which has attracted more and more companies to attend into the area of IOT. As far as I know, governments all over the world have been concerning about IOT, many of who have devoted a great number of money and time to IOT.

United States, one of the biggest countries of science and technology, always take care about development of IOT. In 2005, the plane of "Smart dust" had been viewed as a R\&D project by United States Department of Defense [5]. On February 17, 2009, the president of United States, Barack Obama signed a new law, which was named "American Recovery and Reinvestment Act". It will help technology of IOT to be on the way of high speed.

The European Commission calls for a package deal to develop the technology of IOT. Firstly, the European Commission reported the plan of "i2010" in 2005 [6], which was the new policy of communication. Secondly, the European Commission released the strategy of IOT in 2009. Thirdly, it will spend the European Commission euro 900m to support development of IOT's industry in the future years. "Internet of Things in 2020" (see the following table) means the European Commission will devote a large number of funds and energies to develop the technology of IOT. 
Table 1 Development of the Internet of Things

\begin{tabular}{|l|l|l|l|l|}
\hline & $\begin{array}{l}\text { Wide Take Up Of } \\
\text { RFID:2010 }\end{array}$ & $\begin{array}{c}\text { Integration Of } \\
\text { Objects:2010-2015 }\end{array}$ & $\begin{array}{c}\text { Internet Of } \\
\text { Things:2015-2020 }\end{array}$ & $\begin{array}{l}\text { Potential Of Internet } \\
\text { Of Things:2020- }\end{array}$ \\
\hline $\begin{array}{l}\text { Vision } \\
\text { Technology }\end{array}$ & $\begin{array}{l}\text { Low power and } \\
\text { cost }\end{array}$ & $\begin{array}{l}\text { Ubiquitous integration } \\
\text { of tags }\end{array}$ & $\begin{array}{l}\text { Code in tags and } \\
\text { objects }\end{array}$ & $\begin{array}{l}\text { Smart } \\
\text { everywhere }\end{array}$ \\
\hline Politics & $\begin{array}{l}\text { First global } \\
\text { guidance }\end{array}$ & First policy & Authentication trust & Inclusive \\
\hline Standards & Network security & $\begin{array}{l}\text { Interoperability } \\
\text { protocols }\end{array}$ & Intelligent devices & Health security \\
\hline Use & $\begin{array}{l}\text { RFID adoption in } \\
\text { logistics }\end{array}$ & $\begin{array}{l}\text { Increased } \\
\text { interoperability }\end{array}$ & Global applications & Unified network \\
\hline Devices & $\begin{array}{l}\text { Smaller and } \\
\text { cheaper tags }\end{array}$ & Increasing memory & Ultra high speed & Cheaper materials \\
\hline Energy & Reduced & Improved & Renew & Elements \\
\hline
\end{tabular}

During 2000 and 2009, the Japanese government had made three strategic plans about IOT, which named "e-Japan", "U-Japan" and "I-Japan" (see the following figure). Japanese government want to hold on to keep a dominant position in a hemisphere of science and technology by these plans.

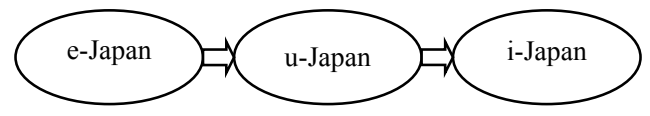

Figure 2. The Internet of Things in Japan

The Fifth Plenary Conference of Sixteenth Central Committee of the CPC brought forward that, strengthening self-directed innovation should be considered as a national strategy, Development Plan Outline for Medium and Long Term Science and Technology Development (2006-2020) also pointed out that, improving self-directed innovation capability should be considered as essentiality for adjusting economic structure, transiting increase mode and improving competitiveness of the State, and constructing innovative country should be taken as the great strategic choice for the future.

Under this general policy, scientific researchers have been working hard on technology of IOT for many years [7]. Thankfully, the CPU "Dragon 1" was successful developed in 2009, which means we have important breakthrough in the areas of IOT. At the same time, International Standards of technology of IOT was formulated under China, Germany, Korea and America. In recent years, the Central Government and the provincial and municipal governments enforce the support to the IOT (see the following table).

Table 2 The Internet of Things in China

\begin{tabular}{|c|c|c|}
\hline $\begin{array}{c}\text { Number of Provinces, } \\
\text { Municipalities or } \\
\text { Autonomous regions }\end{array}$ & Number of cities & $\begin{array}{c}\text { Number of IOT's } \\
\text { projects }\end{array}$ \\
\hline 28 & 52 & 174 \\
\hline
\end{tabular}

In report of government work of 2011, the premier Wen indicated that it is important to develop the merge of the telecommunication, internet and TV network (see the following figure), which is order to promote application of IOT. It is no doubt that, the market of IOT has leapt forward in recent years under influence of those measures [8]. 


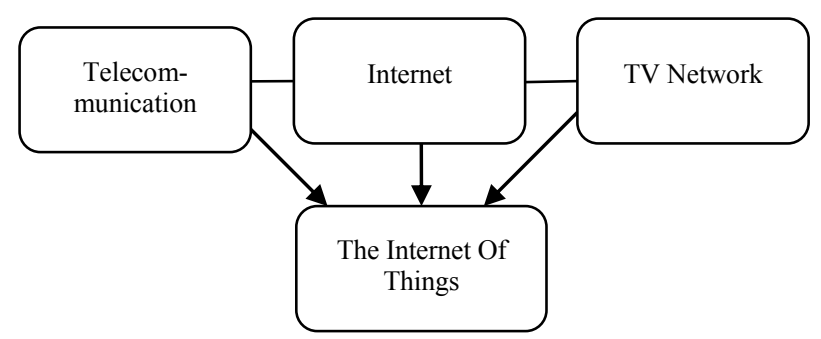

Figure 3. Merge of Communications

\section{Game Theory on the Relationship between Demand and Supply of IOT}

As governments are sparing no efforts in policies and funding to promote IOT, the market of IOT has entered into an accelerating period. After that, relationship of demand and supply influence the development of IOT. The author select Game tool to analysis this influent [9]. As been well known, modern study on Game Theory started form Zermelo (1913), Borel (1921) and von Neumann (1928) [10]. Later Game Theory was introduced into field of economics by Morgenstern [11], who was a famous American economist. Then some economists such as John Nash tried their best to make the Game Theory to be one of the most important tools in the field of economics [12].

\subsection{The Method of Game Analysis}

When we use the tool of Game to analysis relationship between demand and supply [13]. It is important to know two parties of the Game at first: IOT's R\&D companies and consumers in the market. A fundamental assumption of Game method is illustrated as following (see the following figure) :

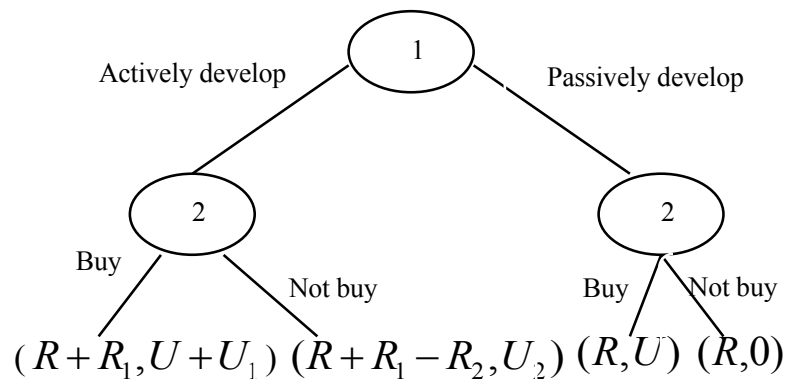

Figure 4. Game of Consumers and Companies

1) Assumption two parties of the Game: $R \& D$ companies (are presented by 1) and consumers (are presented by 2).

2) Assumption two parties of the Game are rational.

3) $R \& D$ companies (1) have two tactics: either actively develop or passively develop.

4) consumers (2) also have two tactics: either purchase services of IOT or do not purchase services of IOT.

5) $R:$ (IOT's companies) income in the context of passively develop.

6) $R_{1}$ : (IOT's companies) income in the context of actively develop.

7) $R_{2}$ : loss in the context of (IOT's companies) actively develop while (consumers) do not buy.

8) $U$ : (consumers) income in the context of (IOT's companies) passively develop. 
9) $U_{1}$ : (consumers) additional income in the context of (IOT's companies) actively develop.

10) $U_{2}$ : (society) loss in the context of (IOT's companies) actively develop while (consumers) do not buy.

11) $p$ : probability of active development of IOT's companies.

12) $q$ : probability of consumers' purchase.

This paper assumes $E_{1}$ as the utility of the companies of the Internet of Things, which can be illustrated as:

$$
\begin{aligned}
E_{1}= & p\left[q\left(R+R_{1}\right)+(1-q)\left(R+R_{1}-R_{2}\right)\right] \\
& +(1-p)[q R+(1-q) R] \\
E_{1} & =p R_{1}-p R_{2}+p q R_{2}+R .
\end{aligned}
$$

We can taking the first-order derivatives about $q$ :

$$
\frac{\partial E_{1}}{\partial p}=R_{1}-R_{2}+q R_{2}
$$

When the utility of companies achieve maximum, the Eq.(2) can be written as:

$$
\frac{\partial E_{1}}{\partial p}=0
$$

Then, probability of consumers' purchase can be calculated as:

$$
q=1-\frac{R_{1}}{R_{2}}
$$

Similarly, assuming $E_{2}$ as the utility of consumers, which can be illustrated as:

$$
\begin{aligned}
& E_{2}=q\left[p\left(U+U_{1}\right)+U(1-p)\right] \\
& +(1-q)\left(p U_{2}+O\right) \\
& E_{2}=p q U_{1}+q U+p U_{2}-p q U_{2} .
\end{aligned}
$$

Taking the first-order derivatives about $p$ :

$$
\frac{\partial E_{2}}{\partial q}=p U_{1}+U-p U_{2}
$$

When the utility of consumers achieve maximum, the Eq.(6) can be written as: 


$$
\frac{\partial E_{2}}{\partial q}=0
$$

Then, probability of active development of IOT's companies can be calculated as:

$$
p=\frac{U}{U_{2}-U_{1}} \text {. }
$$

\subsection{The Result of Game Analysis}

Several valuable conclusions can be obtained by analyzing the changes of $q$ and $p$. For $q=1-\frac{R_{1}}{R_{2}}$, when $R_{2}$ is increasing and $R_{1}$ remains stable, $q$ will become bigger and bigger, which means consumers' desire for consumption will increase and further stimulate the company of IOT developing actively.

For $p=\frac{U}{U_{2}-U_{1}}$, when $U_{2}$ is dropping and $U_{1}$ is increasing, $p$ will become bigger and bigger, which means more and more IOT's companies have motive force to develop technology of IOT. Based on the above analysis, the probability of consumers' purchase increases obviously while the probability of IOT' development increases firstly and decreases afterwards. In that case we proved two equilibriums: (purchase, actively develop), (purchase, passive develop), which can be illustrated by the following table:

Table 3 Equilibriums of Consumers and Companies

\begin{tabular}{|c|l|l|l|}
\hline & \multicolumn{3}{|c|}{ Consumers } \\
\hline \multirow{2}{*}{$\begin{array}{c}\text { Internet of Things's } \\
\text { Companies }\end{array}$} & \multicolumn{1}{c|}{ buy } & Not buy \\
\cline { 2 - 4 } & actively develop & $R+R_{1}, U+U_{1}$ & $R+R_{1}-R_{2}, U_{2}$ \\
\cline { 2 - 4 } & Passively develop & $R, U$ & $R, 0$ \\
\hline
\end{tabular}

It is obvious that purchase intentions of consumers are increasing [14]. In order to gain an advantage, the companies of the Internet of Things try their best to develop technology of IOT. But while purchase intentions of consumers reach a fairly high level [15], intentions of development of those companies are dropping. At last it forms non-virtuous circle (see the following figure): vigorous requirement do not come to good results for development of IOT all the time. In this view, excessive demand of the market does not good for development of IOT.

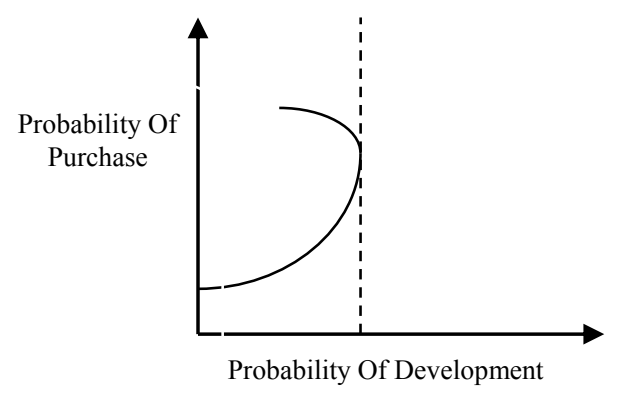

Figure 5. Example of Change of Purchase and Development 


\section{Conclusion}

The Internet of Things is a technological revolution that represents the future of computing and communications, and its development depends on dynamic technical innovation in a large number of important fields, from wireless sensors to nanotechnology.

In the current vision, the IOT will bring an even more pervasive revolution than any other things [16], such as the Internet and mobile technologies and today's acclaimed Information Era. For one thing the future ubiquitous IOT will make possible for virtually any object around us to exchange information and work in synergy to increase dramatically the quality of our lives [17]. For another, fluctuation of market demand impacts the development of IOT's industry. To sum up the above arguments, it is of necessity to coordinate the relationship between demand and supply, only in this way can development of IOT have a bright future.

\section{References}

[1] Li Hong, The Internet of Things-innovation of productive forces, Beijing: Posts \& telecom press, 2010, pp.1-2.

[2] Wu Gongyi, Intelligent Internet of Things-perception technology of China and World, Beijing: China machine Press, 2010, pp.12-14.

[3] Ning Huansheng, The major project of RFID and the Internet of Things of the state, Beijing: China machine Press, 2009.

[4] Zhu Jinzhi, Intelligent Cloud computing: foundation of development of the Internet of Things, Beijing: publishing house of electronics industry, 2010.

[5] China telecom, Approach the Internet of Things, Beijing: Posts \& telecom press, 2010 pp.1-3.

[6] Zhou Sheng, Logistics information and the Internet of Things construction, Beijing: publishing house of electronics industry, 2009.

[7] Nin Jinsheng, Digital city, Beijing: publishing house of electronics industry, 2008.

[8] Wu Jichuan, Information technique and information industry, Beijing: Xinhua Press, 2000.

[9] Geoffrey A.Jehle and Philip J.Reny, Advanced microeconomic theory, Shanghai: Shanghai university of Finance and Economics Press, 2002.

[10]Geoffrey A.Jehle and Philip J.Reny, Advanced microeconomic theory, Shanghai: Shanghai university of Finance and Economics Press, 2002.

[11]Neumann.J.V and Oskar Morgenstern, Game Theory and Economic Behavior, Shanghai: San Lien Press, 2005.

[12] Yang Rongji, Dynamic cooperate-sophisticated Game Theory, Beijing: China Market Press, 2007.

[13] Myerson R.B, Game Theory, Beijing: China machine Press, 2001.

[14]Rodica Branzei, Dinko Dimitrov, and Stef Tijs, Models in Cooperative Game Theory, Germany: Springer-Verlag, 2008.

[15]Bezalel peleg and peter Sudhölter, Introduction to the Theory of Cooperative Games, Germany: Springer-Verlag, 2007. 
[16]Dong Zhiqiang, Game Theory around us, Beijing: China machine Press, 2009.

[17] Tan Chongtai, Introduction to development economics, Wuhan: wuhan university press, 2001. 